\title{
Correction to: SwarmCity project: monitoring traffic, pedestrians, climate, and pollution with an aerial robotic swarm
}

\author{
Juan Jesús Roldán-Gómez ${ }^{1,2} \cdot$ Pablo Garcia-Aunon ${ }^{1} \cdot$ Pablo Mazariegos $^{1} \cdot$ Antonio Barrientos $^{1}$
}

Published online: 21 December 2020

(C) Springer-Verlag London Ltd., part of Springer Nature 2020

\section{Correction to: Personal and Ubiquitous Computing} https://doi.org/10.1007/s00779-020-01379-2

In the original document, the affiliation of the authors was written as:

Centre for Automation and Robotics (UPM-CSIC), Technical University of Madrid, José Gutiérrez Abascal, 2,28006 Madrid, Spain

However, as our institution made us known, the correct way of naming it is:
Centre for Automation and Robotics (CAR), Universidad Politécnica de Madrid (UPM), José Gutiérrez Abascal, 2,28006 Madrid, Spain

The online version of the original article can be found at https://doi.org/10.1007/s00779-020-01379-2.

Publisher's note Springer Nature remains neutral with regard to jurisdictional claims in published maps and institutional affiliations.

The online version of the original article can be found at https://doi.org/ 10.1007/s00779-020-01379-2

Juan Jesús Roldán-Gómez

jj.roldan@upm.es; juan.roldan@uam.es

Pablo Garcia-Aunon

pablo.garcia.aunon@upm.es

Pablo Mazariegos

p.mazariegos@alumnos.upm.es

Antonio Barrientos

antonio.barrientos@upm.es

1 Centre for Automation and Robotics (UPM-CSIC), Universidad Politécnica de Madrid, José Gutiérrez Abascal, 2,

28006 Madrid, Spain

2 Department of Computer Engineering, Autonomous University of Madrid, Francisco Tomás y Valiente, 11, 28049 Madrid, Spain 